Document downloaded from:

http://hdl.handle.net/10251/165274

This paper must be cited as:

Gadea Borrell, JM.; Juliá Sanchis, E.; Segura Alcaraz, JG.; Montava-Belda, I. (2020). Sustainable sound absorbers from fruit stones waste. Applied Acoustics. 161:1-9. https://doi.org/10.1016/j.apacoust.2019.107174

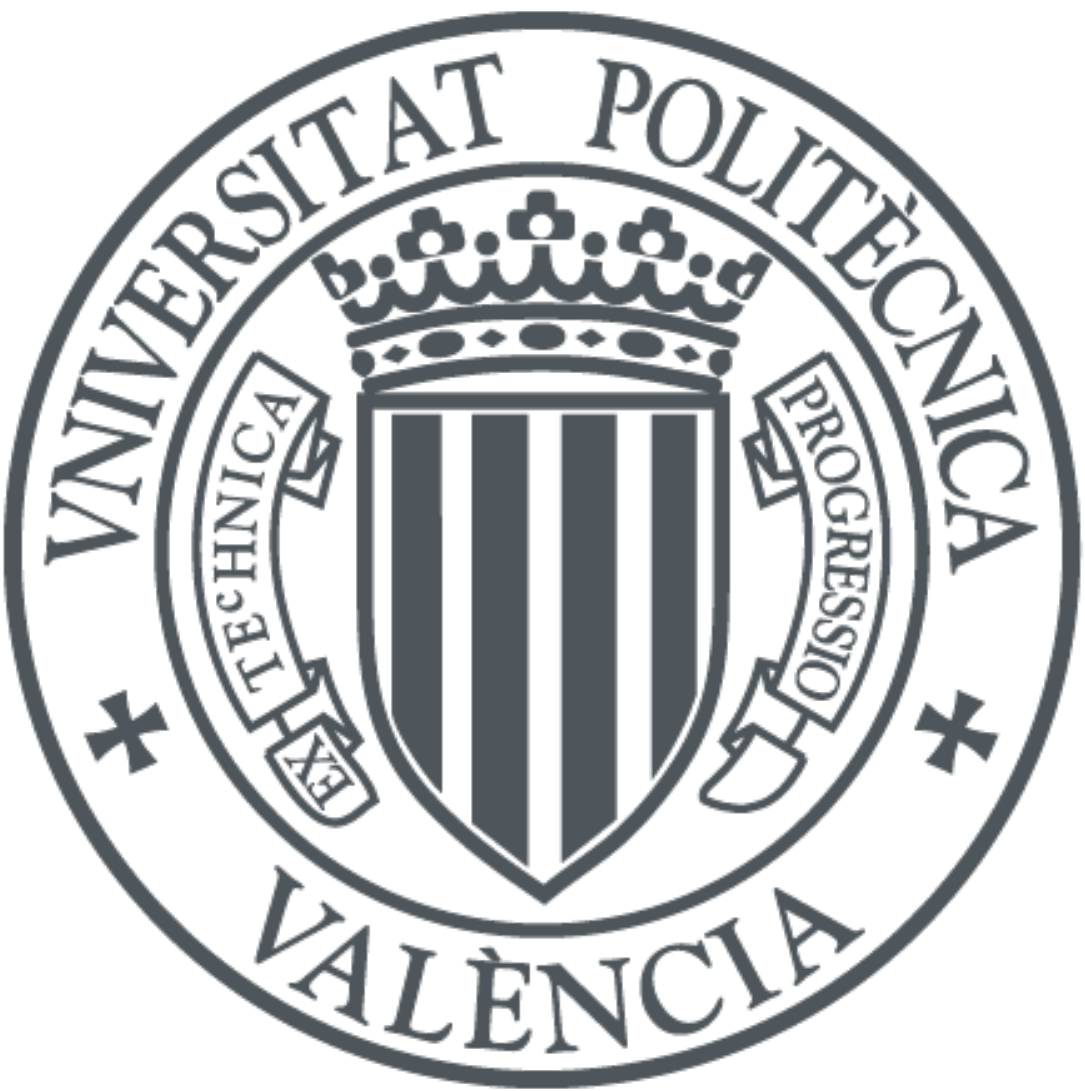

The final publication is available at

https://doi.org/10.1016/j.apacoust.2019.107174

Copyright Elsevier

Additional Information 


\title{
Sustainable sound absorbers from fruit stones waste
}

\author{
J.M. Gadea Borrell, E. Juliá Sanchis, J. Segura Alcaraz, I. Montava Belda
}

Departamento de Mecánica de los Medios Continuos y Teoría de Estructuras. Universitat Politècnica de València, Campus d'Alcoi, Plaza de Ferrándiz y Carbonell, s/n, 03801 Alcoi, Spain.

\begin{abstract}
Ecological and sustainable materials have a growing interest in the field of construction and buildings where recycled materials are being included as constructive solutions. Currently, fruit stones are not used in architectural acoustics and there are no scientific studies that analyse the acoustic insulation of materials manufactured by fruit stones.

This work analyses the sound absorption coefficient of panels made of different fruit stones.

Four types of fruit stones have been selected with different properties in terms of density, shape and porosity. They are of the hard-stone type so that they have a high durability. To determine the sound absorption coefficient, cylindrical samples with different thicknesses have been manufactured and tested in a standing wave tube. The experimental results showed that the sound absorption varies depending on the type of fruit stone and the thickness of the sample.
\end{abstract}

In the frequency range from $550 \mathrm{~Hz}$ to $1500 \mathrm{~Hz}$, some samples reach sound absorption coefficients from 0.7 to 0.95 .

These panels offer good acoustic insulation properties and an added value from the aesthetics point of view.

Keywords: Agricultural waste, fruit stones, sound absorption, acoustic conditioning.

\section{Introduction}

There is an increasing interest in sustainable sound absorbing materials as an alternative to the commonly used ones. These materials reduce the environmental impact in the building industry. Natural materials are intended to increase the sustainability of the buildings [1]. These materials provide the advantage of being largely available and their application in fields as building help to solve the management of the waste. The building sector is integrating new sustainable materials, both for thermal [2][3][4] and acoustic insulation [5][6][7].

There is a wide range of natural materials potentially applied in acoustics as agricultural byproducts [8], [9], kenaf fibres [10], hemp fibres [11], coconut fibres [12][13][14], bamboo fibres [15] or sheep wool [16]. Another type of materials are the ones deriving from agricultural work, as pruning. Some researchers have concentrated their investigations on this type of materials [17]. 
Other natural materials, as fruit bones are being investigated for their application in different sustainable fields, as energy efficiency [18], thermal insulation [19] and production of activated carbon [20][21].

Some natural materials behave as porous absorbers because of their cavities in the internal structure [22][23], which allow absorbing the sound waves at certain frequencies. These type of materials with open pores guarantee the sound absorption properties [24][25][26].

There are different techniques to evaluate the acoustic performance of porous and fibrous materials. One of the most commonly used method consists of characterizing the materials by means of a standing wave tube to determine the sound absorption coefficient at normal incidence [27][28].

Other methods are based on phenomenological models that require parameters as tortuosity, porosity and shape factor of the pore [29][30][31] related to the sound absorption. On the other hand, there are works based on empirical models [32][33][34][35] that relate the experimental sound absorbing values to the predicted ones [36].

The present paper investigates the acoustical behaviour of materials made of fruit stones from different species: olive, cherry, apricot and peach. These fruit trees are typical grown in the Mediterranean area, which makes them largely available.

The samples to be tested are prepared in a circular mould of $100 \mathrm{~mm}$ diameter, which allows determining the sound absorption coefficient in a standing wave tube in the range 200 to $1700 \mathrm{~Hz}$.

\section{Materials}

\subsection{Raw material properties}

The raw materials are fruit stones from different species with a high amount of lignin that provides hardness and durability. These stones are not edible because they are obtained from waste of industrial processes to be used as biomass or to manufacture activated carbon. A cleaning treatment and a subsequent impregnation with a compound of boric salts is required in order to avoid damage by enzymes, insects or xylophagous fungi.

Four different types of fruit stones have been chosen in terms of density, size and surface morphology. These fruits are widely consumed so that a large amount of raw material is available. For this study the chosen fruit stones are olive, cherry, apricot and peach. Table 1 shows the physical properties of these stones.

To determine the average weight of each type of stone, fifty units of each type are weighed and introduced into a test tube calculating the occupied volume of water. The average bulk density is determined from these data (Table 1).

For this study it is necessary to know the amount of bio-resin (FixGrav) required by the stones to prepare the samples. Needles attached to each stone are used to enable the 
soaking (Figure 1). When the resin dries, the stones are weighed again in order to know the dried weight.

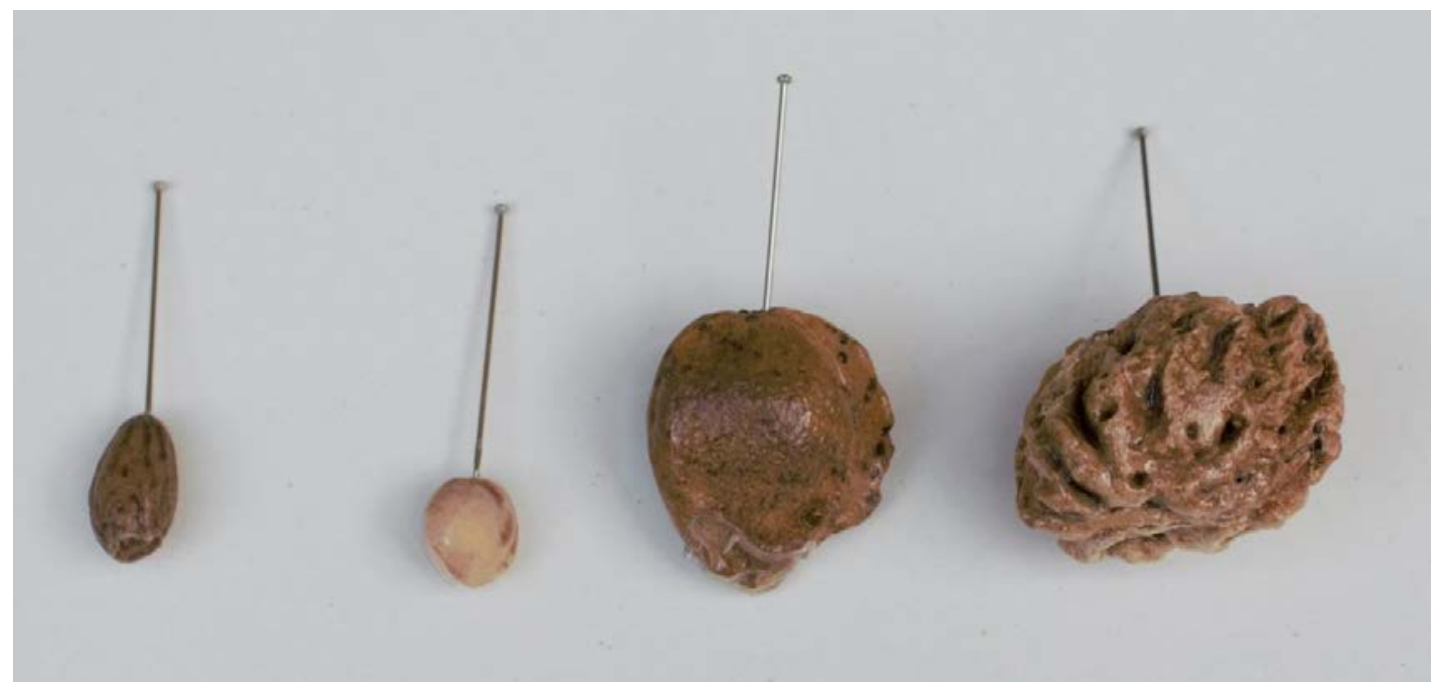

Figure 1. Hard fruit stones with resin.

The average weight loss of the resin when dried is $58.9 \%$. The relationship between the resin and the stone weight for each type of stone is indicated in table 1.

Table 1. Weights and densities of the fruit stones and the resin.

\begin{tabular}{|c|c|c|c|c|}
\hline & OLIVE & CHERRY & APRICOT & PEACH \\
\hline $\begin{array}{l}\text { Weight of } 50 \text { stones } \\
\text { without resin (grams) }\end{array}$ & 22.668 & 14.266 & 83.748 & 159.320 \\
\hline $\begin{array}{l}\text { Volume of } 50 \text { stones } \\
(\mathrm{ml})\end{array}$ & 20 & 17 & 117.5 & 220 \\
\hline $\begin{array}{l}\text { Average weight of a } \\
\text { Stone (grams) }\end{array}$ & 0.453 & 0.285 & 1.675 & 3.186 \\
\hline Density $\left(\mathrm{kg} / \mathrm{m}^{3}\right)$ & 1133.4 & 839.2 & 712.7 & 724.2 \\
\hline $\begin{array}{l}\text { Weight of } 10 \text { stones } \\
\text { without resin and the } \\
\text { needle (grams) }\end{array}$ & 5.203 & 3.810 & 18.397 & 44.113 \\
\hline $\begin{array}{l}\text { Weight of } 10 \text { stones } \\
\text { with the resin and the } \\
\text { needle (grams) }\end{array}$ & 5.720 & 4.180 & 20.297 & 52.357 \\
\hline $\begin{array}{l}\text { Weight of the wet resin } \\
\text { to } 10 \text { stones (grams) }\end{array}$ & 0.517 & 0.370 & 1.900 & 8.244 \\
\hline $\begin{array}{l}\text { Weight of the wet resin } \\
\text { added to } 1 \text { stone } \\
\text { (grams) }\end{array}$ & 0.0517 & 0.0370 & 0.1900 & 0.8244 \\
\hline $\begin{array}{l}\text { Ratio resin weight / } \\
\text { stone weight }\end{array}$ & 0.115 & 0.120 & 0.108 & 0.190 \\
\hline
\end{tabular}


The morphology of the surface of each of these fruit stones can be seen in Figure 2. These images are made by an optical microscope (magnification 50X). It is observed that the olive has a roughness morphology with branched shapes; the cherry stone has a less rough surface; the roughness of apricot stone is quite regular with small holes between half and one-millimetre size; in contrast, the peach stone is the one with the highest roughness and cavities.

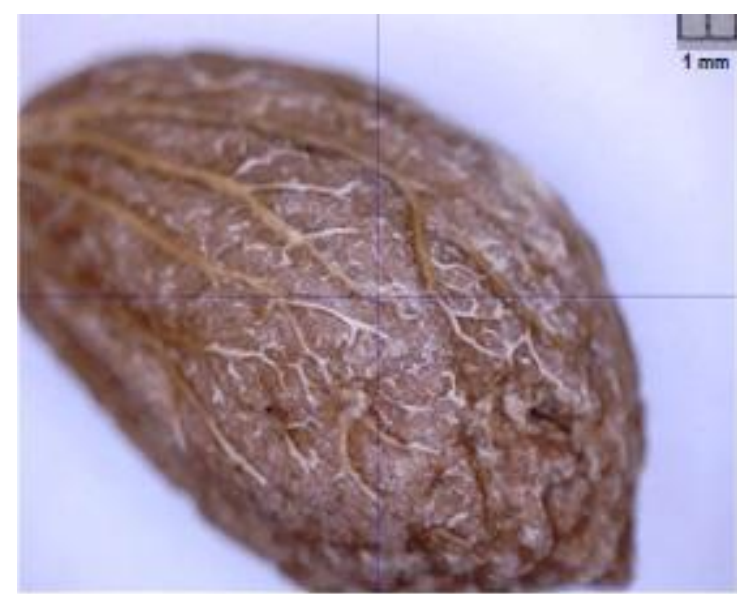

a)

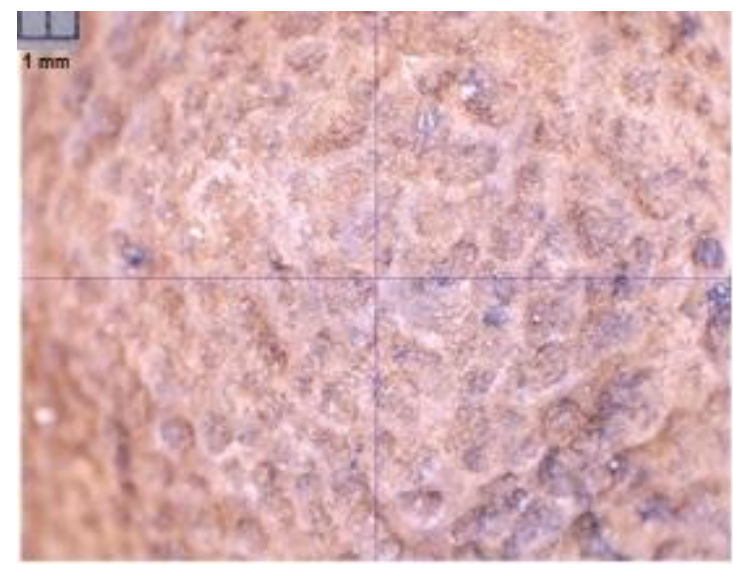

c)

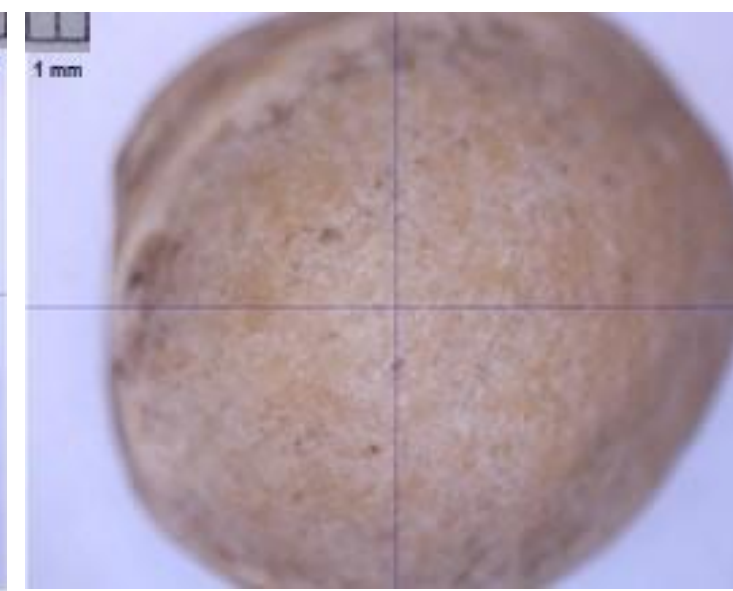

b)

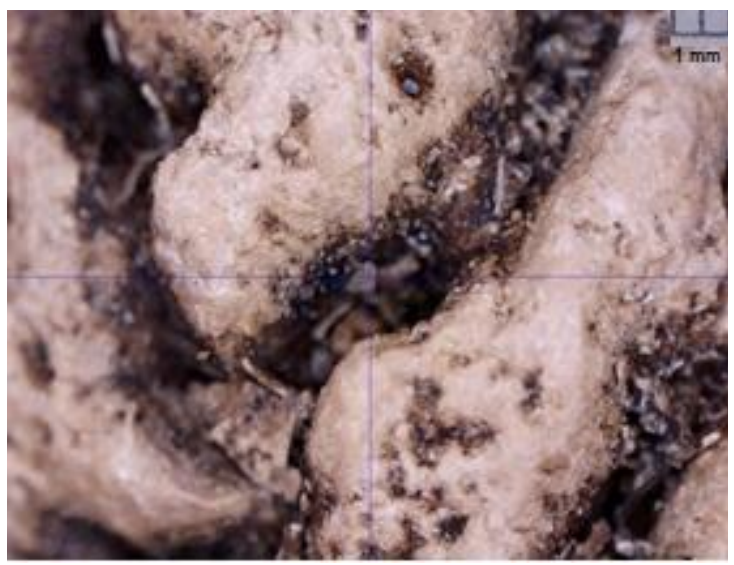

d)

Figura 2. Surface morphology of the fruit stones: a) Olive, b) Cherry, c) Apricot, d) Peach.

To expand the study of the surface morphology of each type of stone, photographs are taken with the JEOL scanning electron microscope model JSM-840 to observe the micropores of the surface (Figure 3). Analysing the JEOL images of each type of fruit stones: the olive stone surface is rough and irregular with small surface cavities; the cherry stone have pores with an average diameter of $0,01 \mathrm{~mm}$; the apricot stone presents a fibrous surface and small cavities; the peach stones have the most percentage of pores compared to the others with an average diameter of $0,5 \mathrm{~mm}$ and an irregular surface. 

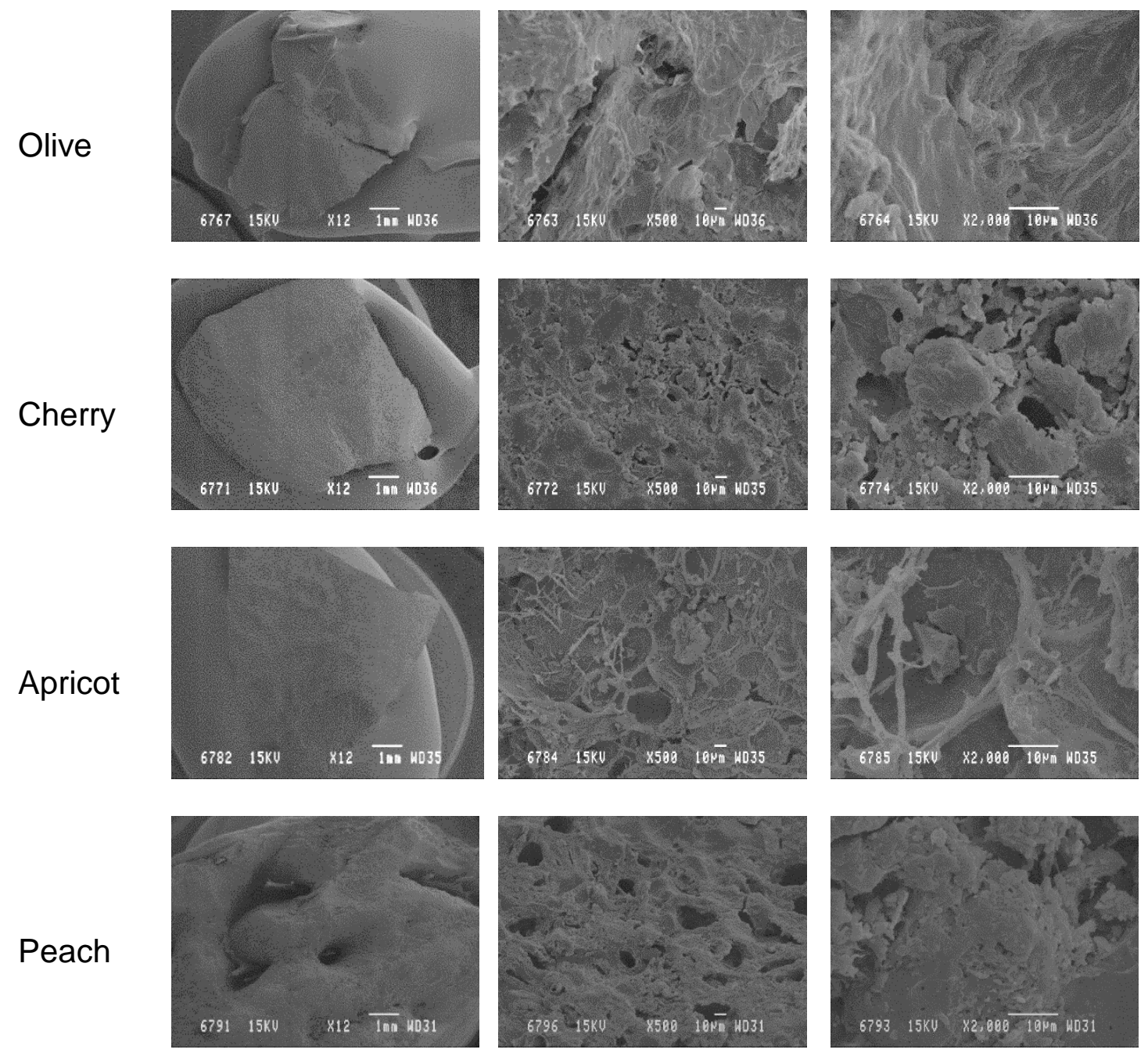

Figure 3. Images of the surface of the fruit stones to $12 x, 500 x$ and $2000 x$ magnification.

\subsection{Samples preparation}

To conduct the sound absorption test, cylindrical samples of $100 \mathrm{~mm}$ diameter and different thicknesses for each type of stone are manufactured (Table 2). The thicknesses in some samples present variations because of the size and shape of each type of fruit stone. The cyanoacrylate adhesive is applied to glue the fruit stones trying to use the minimum amount to minimize the influence in the results. These stones were bonded inside a PVC tube mould.

Table 2 shows the dimensions of each sample, as well as the weights and their bulk density. 
Table 2. Thicknesses, weights and densities of each sample.

\begin{tabular}{|c|c|c|c|c|c|}
\hline Specimen & $\begin{array}{l}\text { Thickness } \\
\text { (mm) }\end{array}$ & $\begin{array}{l}\text { Diameter } \\
\text { (mm) }\end{array}$ & $\begin{array}{c}\text { Weight } \\
\text { (g) }\end{array}$ & $\begin{array}{l}\text { Bulk density } \\
\left(\mathrm{kg} / \mathrm{m}^{3}\right)\end{array}$ & $\begin{array}{c}\text { Weight } \\
\text { with } \\
\text { resin (g) }\end{array}$ \\
\hline Olive-01 & 22 & 100 & 129 & 746.58 & - \\
\hline Olive-02 & 43 & 100 & 243 & 719.53 & - \\
\hline Olive-03 & 55 & 100 & 313 & 724.59 & 323 \\
\hline Olive-04 & 77 & 100 & 435 & 719.30 & - \\
\hline Olive-05 & 98 & 100 & 553 & 718.47 & - \\
\hline \multicolumn{4}{|c|}{ Olive } & 725.61 & \\
\hline Cherry-01 & 24 & 100 & 92 & 488.07 & - \\
\hline Cherry-02 & 42 & 100 & 182 & 551.74 & - \\
\hline Cherry-03 & 55 & 100 & 241 & 557.91 & 250 \\
\hline Cherry-04 & 77 & 100 & 354 & 600.97 & - \\
\hline Cherry-05 & 97 & 100 & 439 & 576.24 & - \\
\hline \multicolumn{4}{|c|}{ Cherry } & 553.66 & \\
\hline Apricot-01 & 24 & 100 & 84 & 445.63 & - \\
\hline Apricot-02 & 40 & 100 & 137 & 436.08 & - \\
\hline Apricot-03 & 55 & 100 & 172 & 398.18 & 179 \\
\hline Apricot-04 & 75 & 100 & 247 & 419.32 & - \\
\hline Apricot-05 & 95 & 100 & 307 & 411.46 & - \\
\hline \multicolumn{4}{|c|}{ Apricot } & 421.79 & \\
\hline Peach-01 & 20 & 100 & 57 & 362.87 & - \\
\hline Peach-02 & 35 & 100 & 99 & 360.14 & - \\
\hline Peach-03 & 55 & 100 & 174 & 391.23 & 211 \\
\hline Peach-04 & 75 & 100 & 212 & 359.90 & - \\
\hline Peach-05 & 95 & 100 & 270 & 361.87 & - \\
\hline (Arithmetic average of bulk density) & \multicolumn{3}{|c|}{ Peach } & 367.01 & \\
\hline
\end{tabular}

Once all the samples have been tested, Olive-03, Cherry-03, Apricot-03 and Peach-03 are soaked with bio-resin to study the variation in the sound absorption coefficient when the resin fills the pores.

Figure 4 shows the corresponding five samples of different thicknesses for each type of fruit stone. 


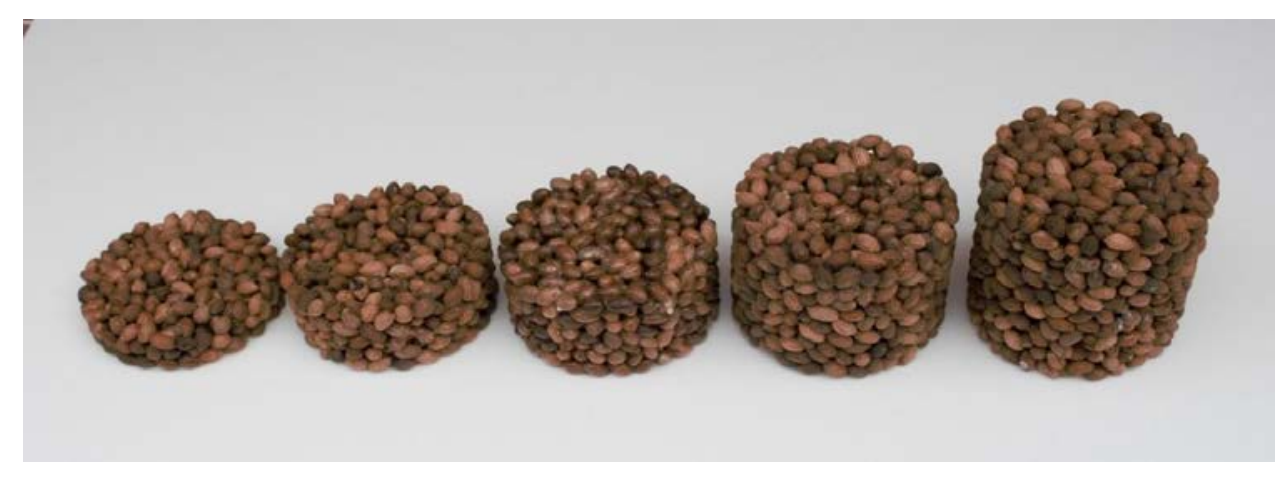

Olive

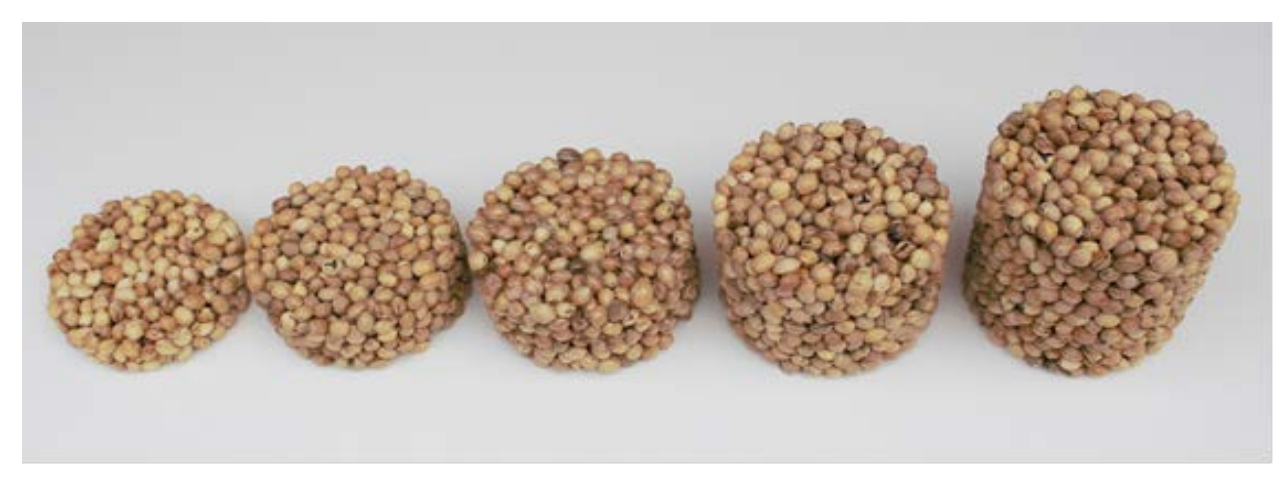

Cherry

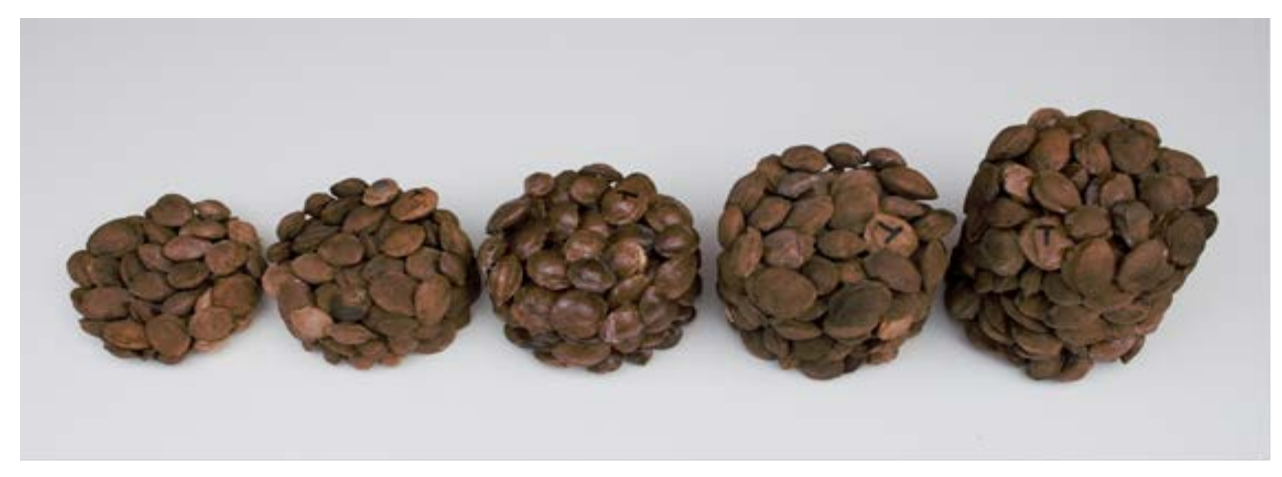

Apricot

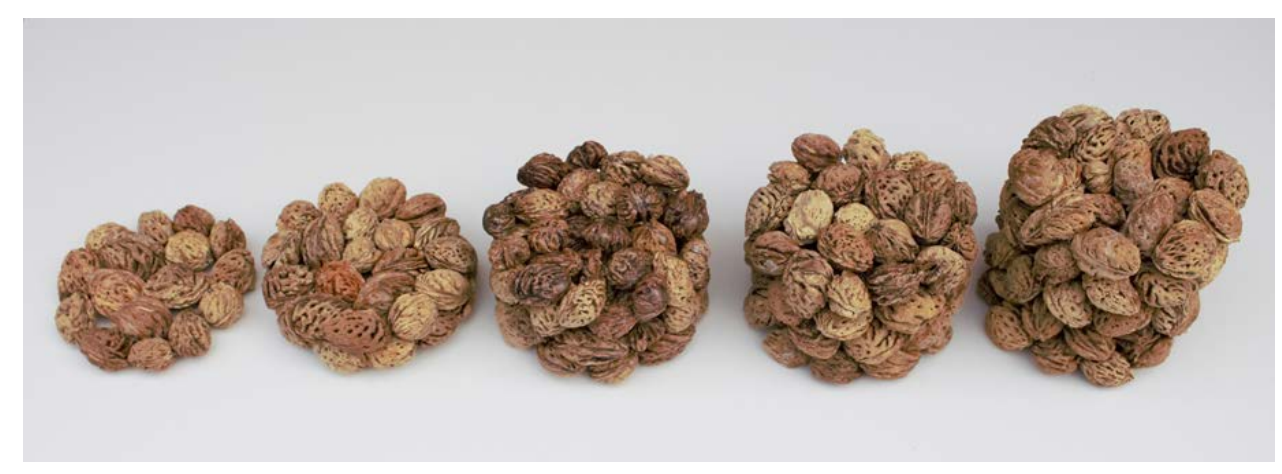

Peach

Figure 4. Studied samples. 


\section{Experimental method}

To determine the sound absorption coefficient in a frequency range between $214.5 \mathrm{~Hz}$ and $1716 \mathrm{~Hz}$, a standing wave tube of an inner diameter 100 millimetres is used, with a distance between microphones of $80 \mathrm{~mm}$.

The frequency range is determined according to the standard ISO 10534-2, which states that the lower frequency depends on the distance between microphones and the higher frequency is limited by the inner diameter of the tube.

The main interest is to study the sound absorption at low frequencies where it is more difficult to reach high absorption coefficients.

The specific acoustic impedance is the ratio of the sound pressure to the specific flow. According to the standard ISO 10534-2, the equipment consists of an impedance tube, which has a constant circular section (inner diameter of $100 \mathrm{~mm}$ ). The sample is located at one end of the tube and a sound source generates plane waves from the other end. Two microphones located close to the sample measure the sound pressures. From the recorded signals, the transfer function is determined to calculate the complex reflection coefficient, the sound absorption coefficient and the acoustic impedance. To calculate the specific acoustic impedance, the following equation is applied:

$\frac{Z}{\rho \cdot c}=\frac{R}{\rho \cdot c}+\frac{X}{\rho \cdot c} j=(1+r) /(1-r)$

$R$, the real component of the impedance.

$X$, the imaginary component of the impedance.

$\rho \cdot c$, characteristic impedance.

$r$, is the reflection coefficient.

$Z$, is the acoustic impedance.

The reflection coefficient is defined as:

$r=\frac{H_{12}-H_{i}}{H_{R}-H_{12}} \cdot e^{2 j k_{0} x_{1}}$

And the sound absorption coefficient is given by:

$$
\propto=1-|r|^{2}
$$

$H_{12}$, is the transfer function from microphone positions 1 and 2, $H_{R}$, is the real part of $H_{12}, H_{i}$ is the imaginary part of $H_{12}, k_{0}$ is the wave number, $x_{1}$ is the distance between the sample and the first microphone.

The frequency range is determined by:

$$
f_{l}<f<f_{u}
$$


$f_{l}$ is the lower frequency of the tube, $f$ is the working frequency, $f_{u}$ is the upper frequency of the tube.

The impedance tube must be long enough to permit waves to be flattened before the sample. The MATLAB software is used for controlling the analogue input and for processing signals.

The schematics set-up of the equipment to conduct the tests is represented in figure 5 . The two microphones are microphones G.R.A.S. model 40AO. The data acquisition card is National Instruments model NI-9233.

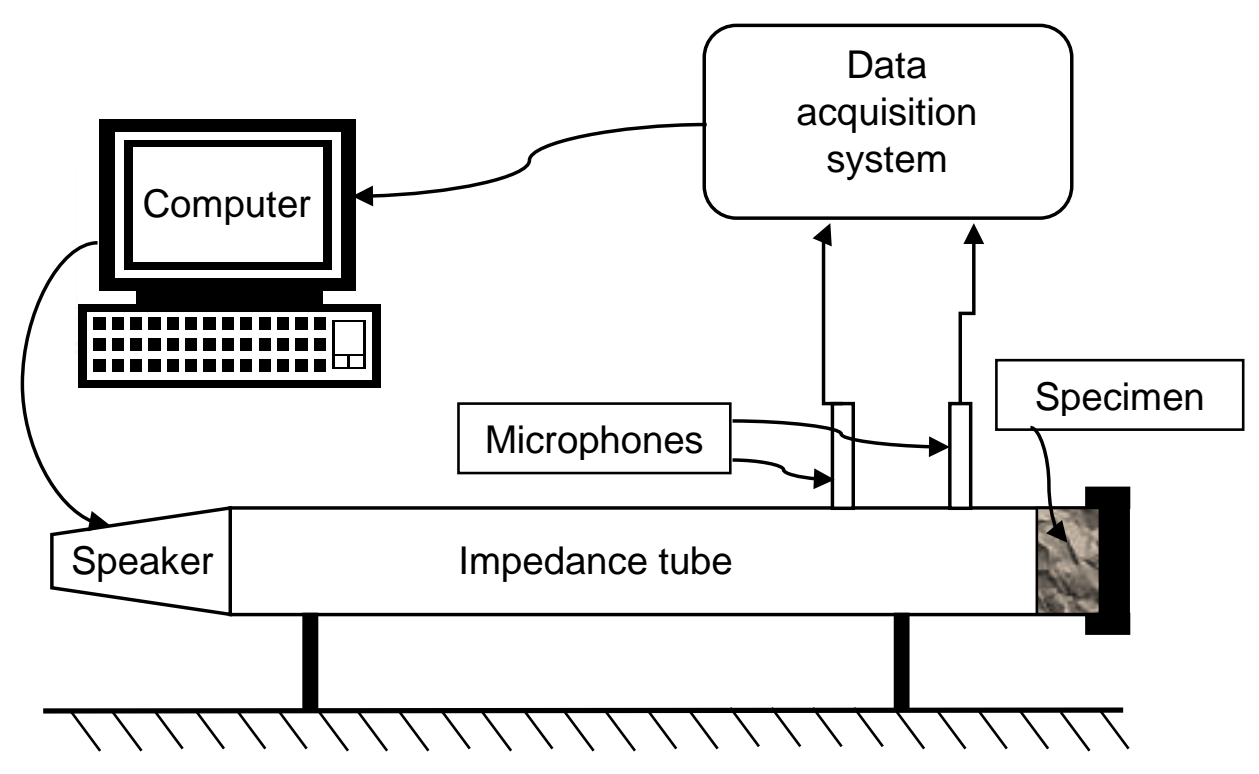

Figure 5. Scheme of the impedance tube to measure the sound absorption coefficient.

\section{Results and discussion}

Figures 6 to 9 represent the sound absorption coefficient of the twenty samples.

In general, when the thickness increases the frequency range of the sound absorption moves to low frequencies. In all cases, the thickness 01 has a negligible sound absorption coefficient in the frequency range studied.

In the case of olive stones, it is observed that the maximum sound absorption coefficient is in the range 0.7 to 0.8 . The maximum sound absorption occurs at a frequency of $725 \mathrm{~Hz}$ with the value of 0.76 for the olive-04 sample. 


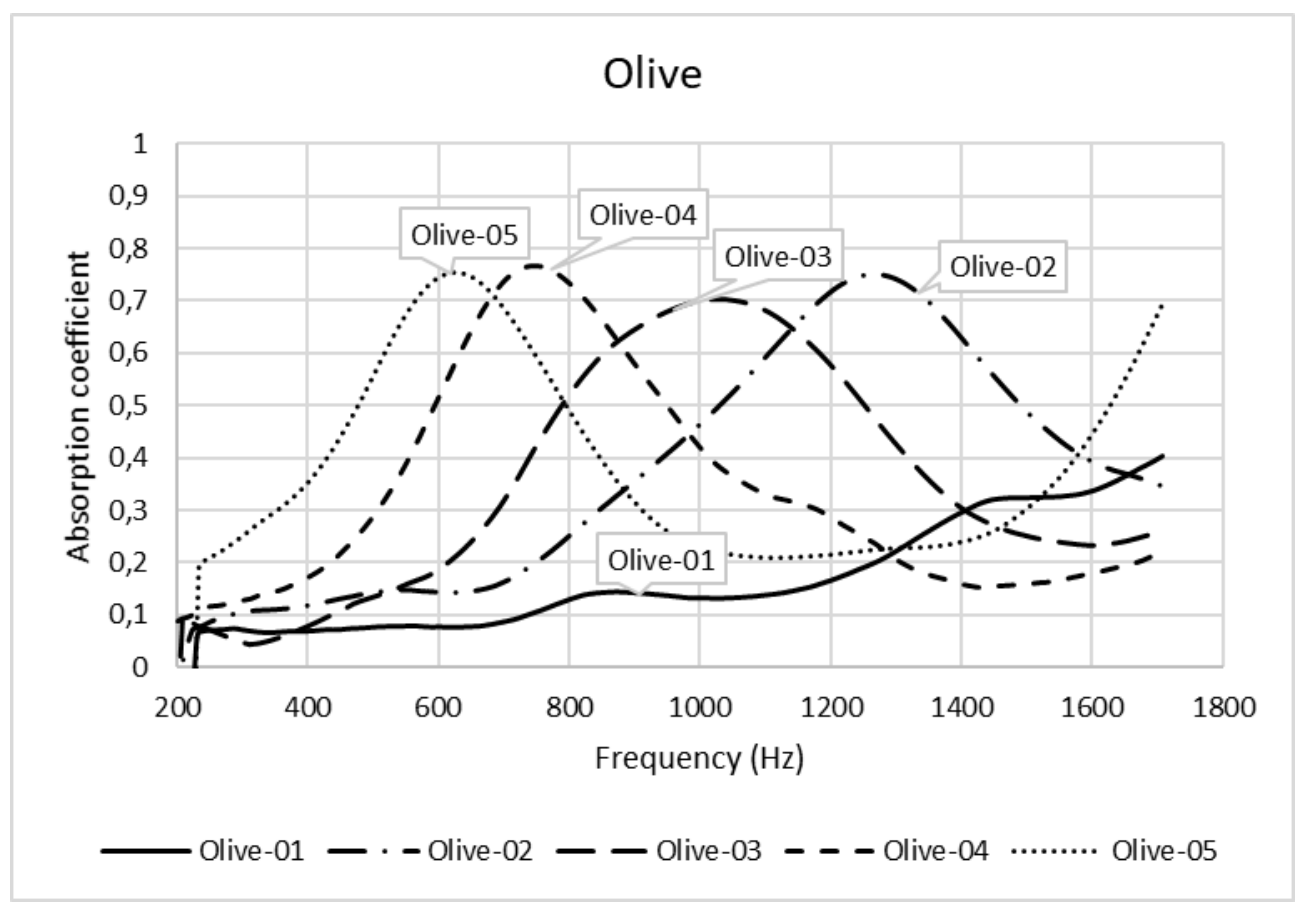

Figure 6. Sound absorption coefficient in olive stones samples.

Regarding cherry stones it is observed that the maximum sound absorption coefficient is in the range 0.8 to 0.9 . The maximum sound absorption occurs at a frequency of $796 \mathrm{~Hz}$ with the value of 0.88 for the cherry-04 sample.

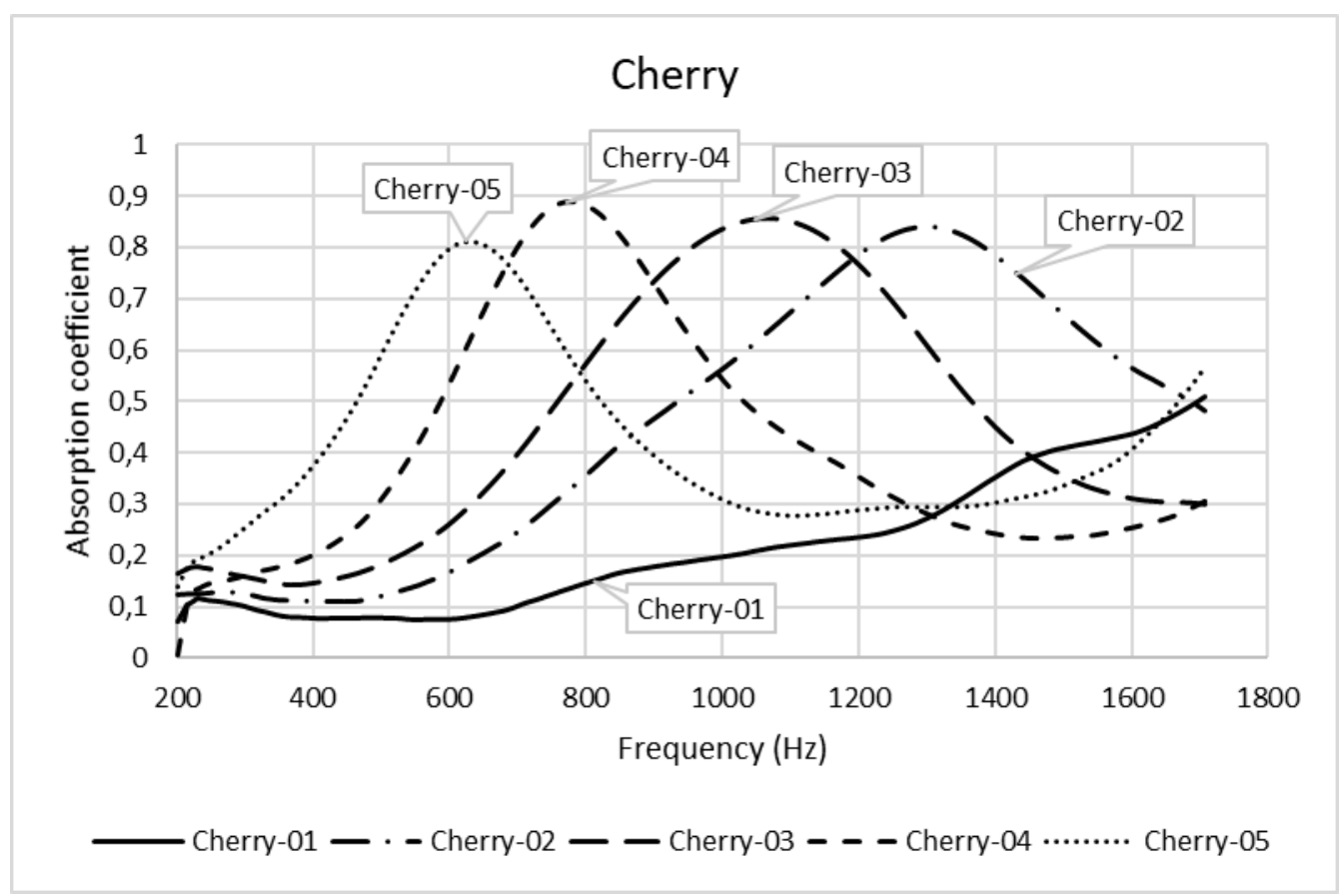

Figure 7. Sound absorption coefficient in cherry stones samples.

For apricot stones it is observed that the maximum sound absorption coefficient is in the range 0.6 to 0.95 . In this case, when the thickness increases, the maximum value of the 
absorption decreases. The maximum sound absorption occurs at a frequency of $1000 \mathrm{~Hz}$ with the value of 0.94 for the apricot-03 sample.

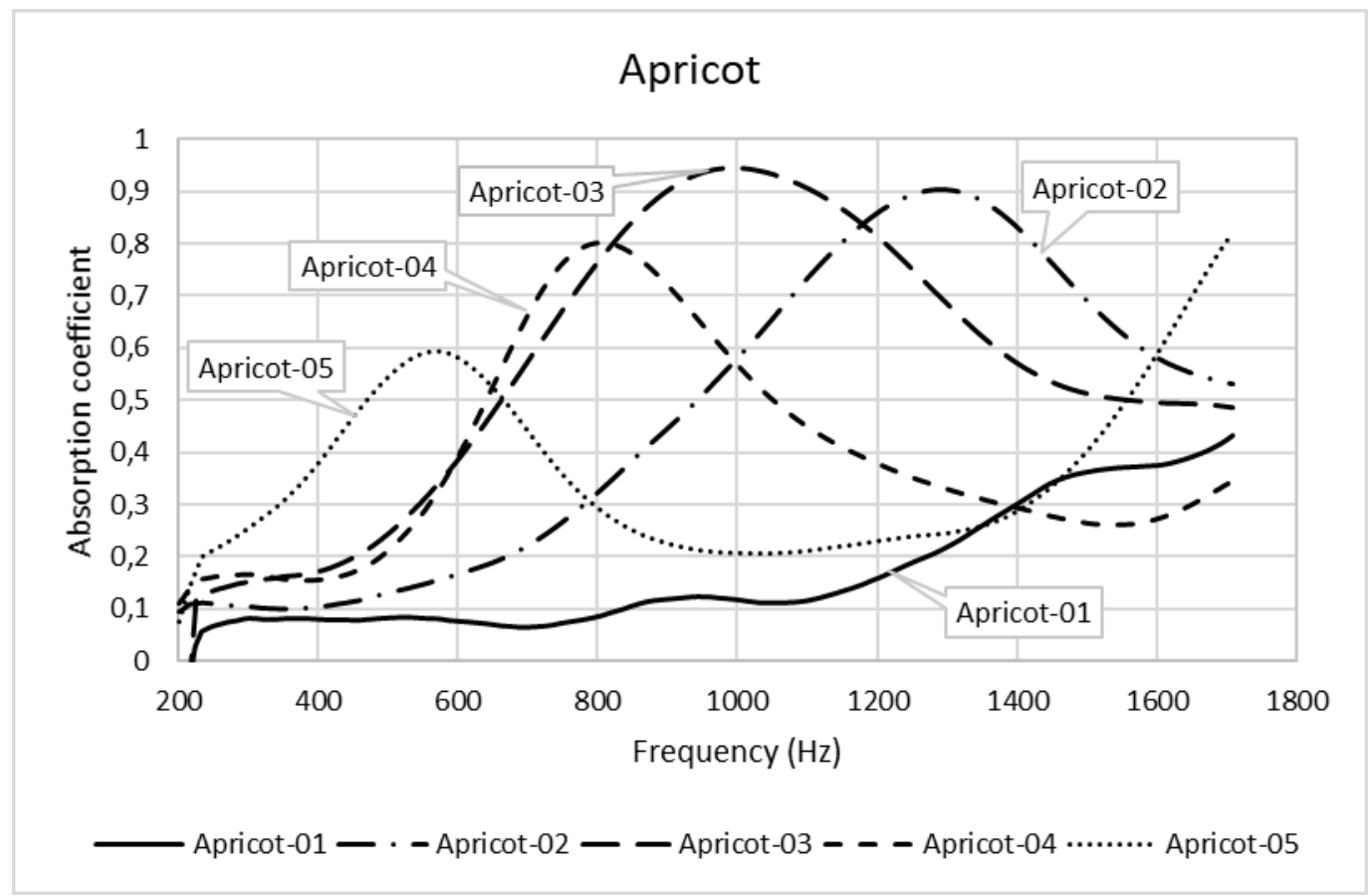

Figure 8. Sound absorption coefficient in apricot stones samples.

Finally, for peach stones it is observed that the maximum sound absorption coefficient is in the range 0.65 to 0.8 . The results given for the peach stones samples are those with the lowest sound absorption coefficients. The maximum sound absorption occurs at a frequency of $1610 \mathrm{~Hz}$ with the value of 0.74 for the peach-02 sample.

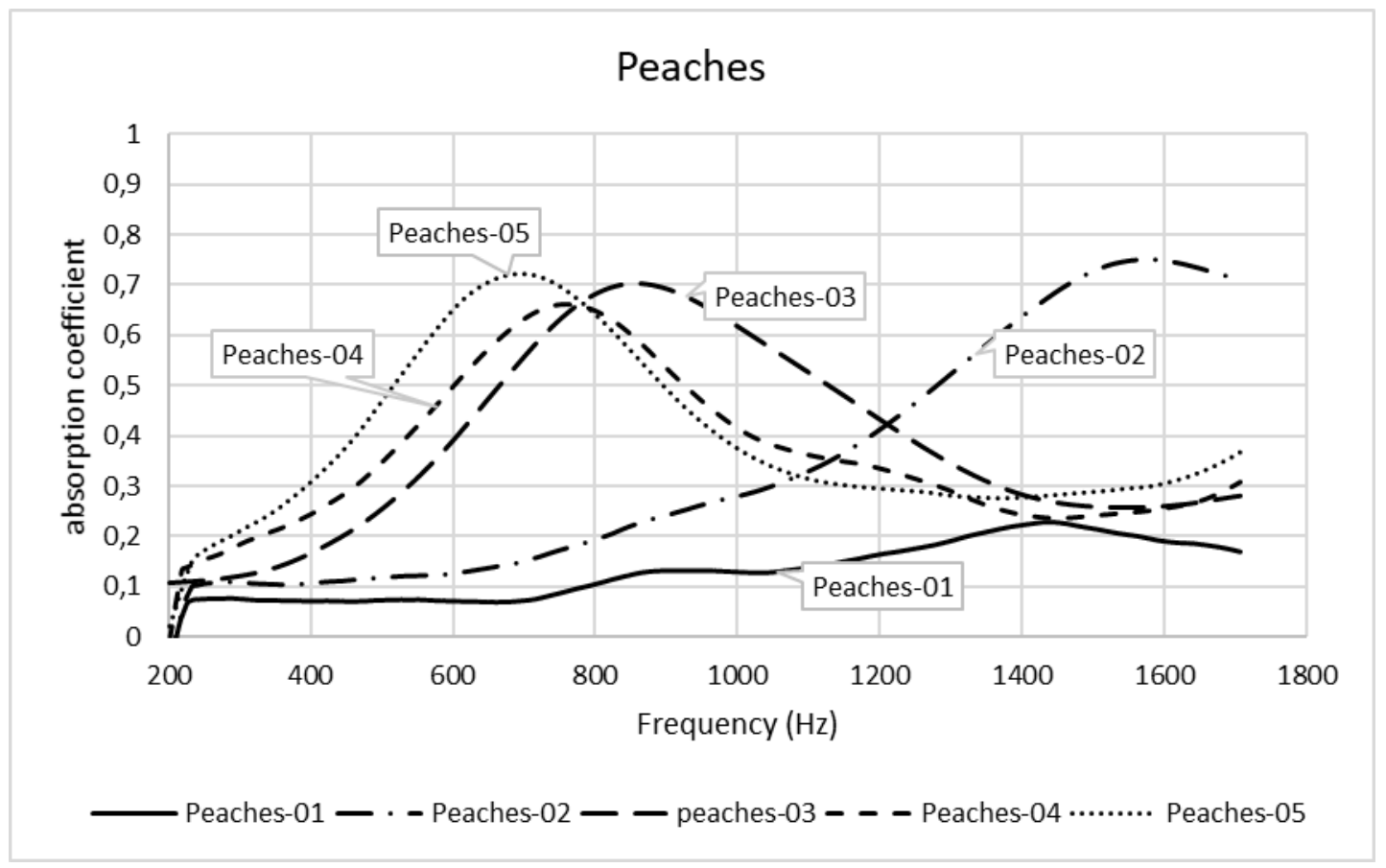

Figure 9. Sound absorption coefficient in peach stones samples. 
Comparing the results of the four types of fruit stones, the behaviour of small stones gives generally higher sound absorption coefficients, especially the cherry stones samples. It is also interesting to note that the thickness and frequency of the maximum sound absorption are quite similar among the four types of fruit stones.

In Table 3, the results of two dimensionless coefficients are analysed: the average sound absorption coefficient, $\alpha \mathrm{M}$, and the proposed low frequency absorption coefficient, $\alpha \mathrm{B}$, which has a higher value if the absorption content is higher at low frequencies. This coefficient is given by the equation:

$\alpha_{B}=\frac{\frac{\sum_{i=1}^{n}\left(f_{i} \cdot \alpha_{i}\right)}{n}}{f_{B}}$

Where $\alpha_{i}$ is the absorption coefficient for each frequency $f_{i}, f_{B}$ is the frequency of the peak with the highest absorption coefficient in the analysed frequency range, and $n$ the number of samples of the signal.

The meaning of this average sound absorption coefficient is to compare the sound absorption performance at low frequencies.

Table 3. Average sound absorption coefficient $\alpha_{\mathbf{m}}$, and low frequency coefficient $\alpha_{\mathbf{B}}$ of the analysed samples.

\begin{tabular}{|c|c|c|c|c|c|c|c|c|}
\hline & \multicolumn{2}{|c|}{ Olive } & \multicolumn{2}{c|}{ Cherry } & \multicolumn{2}{c|}{ Apricot } & \multicolumn{2}{c|}{ Peach } \\
\hline & $\mathbf{\alpha}_{\mathbf{M}}$ & $\mathbf{\alpha}_{\mathbf{B}}$ & $\mathbf{\alpha}_{\mathbf{M}}$ & $\mathbf{\alpha}_{\mathbf{B}}$ & $\mathbf{\alpha}_{\mathbf{M}}$ & $\boldsymbol{\alpha}_{\mathbf{B}}$ & $\mathbf{\alpha}_{\mathbf{M}}$ & $\boldsymbol{\alpha}_{\mathbf{B}}$ \\
\hline 01 & 0.17 & 0.12 & 0.21 & 0.15 & 0.17 & 0.12 & 0.13 & 0.11 \\
\hline 02 & 0.34 & 0.37 & 0.45 & 0.41 & 0.47 & 0.43 & 0.34 & 0.27 \\
\hline 03 & 0.35 & 0.36 & 0.46 & 0.45 & 0.57 & 0.60 & 0.32 & 0.35 \\
\hline 04 & 0.34 & 0.40 & 0.41 & 0.49 & 0.39 & 0.47 & 0.36 & 0.44 \\
\hline 05 & 0.38 & 0.57 & 0.42 & 0.61 & 0.36 & 0.62 & 0.39 & 0.51 \\
\hline Average & $\mathbf{0 . 3 1 6}$ & $\mathbf{0 . 3 6 4}$ & $\mathbf{0 . 3 9 0}$ & $\mathbf{0 . 4 2 2}$ & $\mathbf{0 . 3 9 2}$ & $\mathbf{0 . 4 4 8}$ & $\mathbf{0 . 3 0 8}$ & $\mathbf{0 . 3 3 6}$ \\
\hline
\end{tabular}

The samples of thickness three (olive-03, cherry-03, apricot-03 and Peachs-03) have been coated by immersion with a bio resin binder in order to study the influence of open or closed pore (Figure 10). 

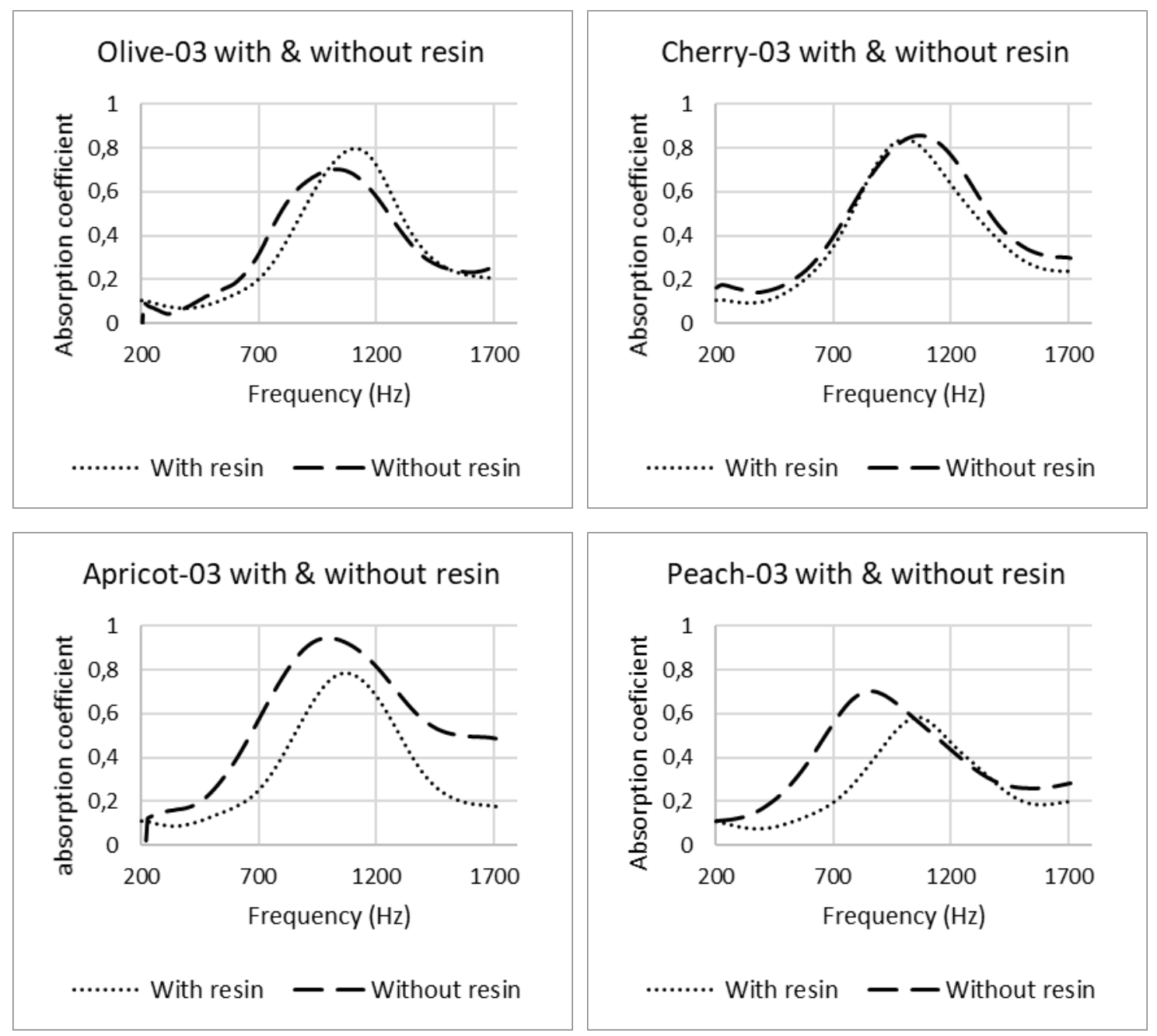

Figure 10. Sound absorption coefficients of the samples (thickness three) with and without resin.

The graphs showed in figure 10 are the results of the sound absorption coefficient of the four samples thickness 03 with and without resin. It can be observed that the resin has little influence in the olive and cherry stones due to the smallest diameters of their pores. In the case of the apricot stones the resin blocks the fibrous structure and this results in a lower sound absorption capability. Finally, the influence of the resin in the peach stones is also noticeable.

In general, it is observed that the sound absorption coefficient has lower values with the coating that closes the pores. The effect is more noticeable in the fruit stones with the bigger pores, like peach and apricot samples.

\section{Conclusions}

In this work, the sound absorption coefficients of samples manufactured with different types of fruit stones have been studied by means of the impedance tube technique.

The measurements conducted on these natural waste materials have shown that these samples have good sound absorption values at low frequencies. The graphs present the 
typical behaviour of resonators. In addition, combining thicknesses, it is possible to achieve significant sound absorption in the range 200 to $1700 \mathrm{~Hz}$.

The investigation has confirmed several findings. One, the sound absorption depends on the shape and size of the fruit stones, being the maximum value for Apricot-03 of 0.94 at $1018 \mathrm{~Hz}$. Two, from the results, a dimensionless coefficient is proposed in order to differentiate the absorption content at low frequencies. With the calculations of the coefficients $\alpha_{M}$ and $\alpha_{B}$ and with the average values for each type of fruit stone it can be observed that the best behaviour in terms of sound absorption at low frequencies corresponds to the apricot and cherry stones. Three, from the observing the graphs, a particular thickness to absorb at a particular frequency could be predicted for each type of stone.

The use of fruit stones as absorptive materials is a valid option to reduce noise and reverberations in buildings. Moreover, the use of this natural waste material presents environmental advantages and can be extended to another type of fruit stones. The study allows to add value to these agricultural crop waste.

Further investigation will be conducted in order to characterize the samples in terms of mechanical, thermal and durability properties.

\section{References}

[1] F. Asdrubali, S. Schiavoni, and K. V. Horoshenkov, "A Review of Sustainable Materials for Acoustic Applications," Build. Acoust., 2012.

[2] S. Panyakaew and S. Fotios, "New thermal insulation boards made from coconut husk and bagasse," Energy Build., 2011.

[3] J. Zach, J. Hroudová, J. Brožovský, Z. Krejza, and A. Gailius, "Development of thermal insulating materials on natural base for thermal insulation systems," in Procedia Engineering, 2013.

[4] F. Barreca and C. R. Fichera, "Use of olive stone as an additive in cement lime mortar to improve thermal insulation," Energy Build., 2013.

[5] A. Patnaik, M. Mvubu, S. Muniyasamy, A. Botha, and R. D. Anandjiwala, "Thermal and sound insulation materials from waste wool and recycled polyester fibers and their biodegradation studies," Energy Build., 2015.

[6] C. Buratti, E. Belloni, E. Lascaro, G. A. Lopez, and P. Ricciardi, "Sustainable Panels with Recycled Materials for Building Applications: Environmental and Acoustic Characterization," in Energy Procedia, 2016.

[7] J. Faustino et al., "Impact sound insulation technique using corn cob particleboard," Constr. Build. Mater., 2012.

[8] M. G. Pelletier, G. A. Holt, J. D. Wanjura, E. Bayer, and G. Mclntyre, "An evaluation study of mycelium based acoustic absorbers grown on agricultural by-product substrates," Ind. Crops Prod., 2013.

[9] M. G. Pelletier et al., "An evaluation study of pressure-compressed acoustic absorbers grown on agricultural by-products," Ind. Crops Prod., 2017.

[10] L. Z. Ying, A. Putra, M. J. M. Nor, and N. Muhammad, "Sound Absorption of Multilayer Natural Coir and Kenaf fibers," 23rd Int. Congr. Sound Vib., 2016.

[11] P. Glé, E. Gourdon, and L. Arnaud, "Modelling of the acoustical properties of hemp particles," Constr. Build. Mater., 2012.

[12] R. Zulkifli, Zulkarnain, and M. J. M. Nor, "Noise control using coconut coir fiber sound 

M. Jailani, M. Nor, N. Jamaludin, and F. M. Tamiri, "A preliminary study of sound absorption using multi-layer coconut coir fibers," Electron. J. «Technical Acoust., 2004.

[14] R. Zulkifli, M. J. Mohd Nor, M. F. Mat Tahir, A. R. Ismail, and M. Z. Nuawi, "Acoustic properties of multi-layer coir fibres sound absorption panel," J. Appl. Sci., 2008.

[15] T. Koizumi, N. Tsujiuchi, and A. Adachi, "The development of sound absorbing materials using natural bamboo fibers," High Perform. Struct. Compos., 2002.

[16] R. del Rey, A. Uris, J. Alba, and P. Candelas, "Characterization of sheep wool as a sustainable material for acoustic applications," Materials (Basel)., 2017.

[17] F. Martellotta, A. Cannavale, V. De Matteis, and U. Ayr, "Sustainable sound absorbers obtained from olive pruning wastes and chitosan binder," Appl. Acoust., 2018.

[18] P. Bartocci, M. D'Amico, N. Moriconi, G. Bidini, and F. Fantozzi, "Pyrolysis of olive stone for energy purposes," in Energy Procedia, 2015.

[19] M. L. Martínez, M. M. Torres, C. A. Guzmán, and D. M. Maestri, "Preparation and characteristics of activated carbon from olive stones and walnut shells," Ind. Crops Prod., 2006.

[20] M. G. Lussier, J. C. Shull, and D. J. Miller, "Activated carbon from cherry stones," Carbon N. Y., 1994.

[21] C. Djilani et al., "Adsorption of dyes on activated carbon prepared from apricot stones and commercial activated carbon," J. Taiwan Inst. Chem. Eng., 2015.

[22] M. A. Kuczmarski and J. C. Johnston, "Acoustic Absorption in Porous Materials," Nasa/Tm-2011-216995, 2011.

[23] J. F. Allard and N. Atalla, Propagation of Sound in Porous Media: Modelling Sound Absorbing Materials. 2009.

[24] K. Attenborough, "Acoustical characteristics of porous materials," Physics Reports. 1982.

[25] J. Arenas and M. Crocker, "Recent Trends in Porous Sound-Absorbing Materials," Noise Vib. Control Mag., 2010.

[26] X. Tang and X. Yan, "Acoustic energy absorption properties of fibrous materials: A review," Composites Part A: Applied Science and Manufacturing. 2017.

[27] International Organization For Standardization, "Acoustics - Determination of sound absorption coefficient and impedance in impedance tubes - Part 1 - Method using standing wave ratio.pdf," Int. Stand., 2001.

[28] B. Standard, "Acoustics-Determination of Sound Absorption Coefficient and Impedance in Impedance Tubes_Part 2: Transfer-Function Method," BS EN ISO, 2001.

[29] J. Allard and Y. Champoux, "New empirical equations for sound propagation in rigid frame fibrous materials," J. Acoust. Soc. Am., 1992.

[30] J. F. Allard, B. Castagnede, M. Henry, and W. Lauriks, "Evaluation of tortuosity in acoustic porous materials saturated by air," Rev. Sci. Instrum., 1994.

[31] Y. Champoux and M. R. Stinson, "On acoustical models for sound propagation in rigid frame porous materials and the influence of shape factors," J. Acoust. Soc. Am., 2005.

[32] M. E. Delany and E. N. Bazley, "Acoustical properties of fibrous absorbent materials," Appl. Acoust., 1970.

[33] Y. Miki, "Acoustical properties of porous materials. Modifications of Delany-Bazley models.," J. Acoust. Soc. Japan, 1990.

[34] W. Qunli, "Empirical relations between acoustical properties and flow resistivity of 
porous plastic open-cell foam," Appl. Acoust., 1988.

[35] R. Del Rey, J. Alba, J. P. Arenas, and V. J. Sanchis, "An empirical modelling of porous sound absorbing materials made of recycled foam," Appl. Acoust., 2012.

[36] D. Oliva and V. Hongisto, "Sound absorption of porous materials - Accuracy of prediction methods," Appl. Acoust., 2013. 